60 patients have presented to our rheumatology department with gout: 51 men, mean age 55.2 years and mean age of onset 46.6 years and nine women, mean age 80 years and mean age of onset of 78.6 years. We studied the prevalence of hyperlipidaemia, hypertension, obesity, and cardiovascular disease in these two groups.

Eighteen men but none of the women had a significant hyperlipidaemia. Triglycerides were by far the most common lipids (type IV) to be raised, being found in 13 of the 18. Four had hypercholesterolaemia: two type IIa and two type IIb (serum triglycerides also raised). One patient had a pronounced rise of serum triglyceride and cholesterol due to accumulation in serum of intermediate density lipoproteins, type III hyperlipidaemia or broad $\beta$-disease.

Six men described themselves as teetotal, but three of these had a hyperlipidaemia. One had type IIa and had had a myocardial infarction at the age of 42 , the other two had type IV. One of these, the hospital's appliance officer, was within the range of his ideal body weight and therefore corresponded to those patients described by Dr Darlington (p. 90) with lean, dry gout. The other was massively overweight at $144 \mathrm{~kg}$. None of the women drank on a regular basis but several did admit to the occasional sherry at Christmas, or the odd glass of Guinness as a 'tonic'. Only one of the women was above her ideal body weight, the remainder tending to be thin and frail.

Twenty men and two women had hypertension, defined as a resting diastolic blood pressure above 100 $\mathrm{mmHg}$ on two or more occasions, or receiving established treatment for hypertension. The patients were questioned about history of myocardial infarction and symptoms of angina. They were examined for signs of peripheral vascular disease and all underwent electrocardiography. On this basis 10 men and three women had appreciable cardiovascular disease. This did not correlate with hyperlipidaemia except in the two patients with type IIa, and nor did it correlate with hypertension.

These observations are on a small number of patients and the study was uncontrolled, but the interesting fact that emerges is the great disparity in the ages of the men and women presenting with gout and the virtual absence of associated factors such as obesity, hypertension, and hyperlipidaemia in the elderly women. This could be interpreted as implying two quite separate disease processes in the two groups. It may be significant in this regard that all the women were receiving potent diuretic treatment. An alternative explanation could be that women are much more prone to cardiovascular disease in association with gout and many had died at a younger age; this, however, is contrary to clinical experience.

\section{References}

1 Grahame R, Scott J T. Clinical survey of 354 patients with gout. Ann Rheum Dis 1970; 29: 461-7.

2 Persky T W, Dyer D R, Idris-Soven E, et al. Uric acid: a risk factor for coronary heart disease? Circulation 1979; 59: 969-76.

3 Macfarlane D G, Slade R, Hopes P A, Hartog M. A study of platelet aggregation and adhesion in gout. Clinical and Experimental Rheumatology 1982 (in press).

\title{
Study of blood coagulation in gout patients
}

\author{
D. A. LANE, AND L. G. DARLINGTON \\ From the Charing Cross Hospital, London, and Epsom District Hospital, Epsom, Surrey
}

Patients with gout have vascular risk factors such as hyperlipidaemia, hypertension, 'type A' personality, and, possibly, hyperuricaemia, obesity, and glucose intolerance. We used a modern method to seek abnormalities of coagulation in patients with gout.

Twelve fasting men with primary gout were studied. Patients were asked to take no medication, particularly aspirin, for the two weeks preceding the tests. No patients were included within three months of trauma or surgery and an atraumatic venepuncture technique was used.

Assays were performed to fibrinopeptide $A(F p A)^{1}$ with
Table 1 Comparison of mean data from patients with gout and from controls

\begin{tabular}{|c|c|c|c|}
\hline & Controls & $\begin{array}{l}\text { Patients } \\
\text { with gout }\end{array}$ & Significance \\
\hline \multicolumn{4}{|c|}{$\mathrm{FpA}(\mathrm{pmol} / \mathrm{l})$} \\
\hline No. & 13 & 10 & \multirow{3}{*}{ NS } \\
\hline Mean & 0.98 & $1 \cdot 53$ & \\
\hline SD & $0 \cdot 29$ & 0.77 & \\
\hline \multicolumn{4}{|c|}{$\mathrm{FpB} \beta 1-42(\mathrm{pmol} / \mathrm{l})$} \\
\hline No. & 10 & 9 & \multirow{3}{*}{ NS } \\
\hline Mean & $1 \cdot 65$ & $2 \cdot 92$ & \\
\hline SD & 0.63 & 1.85 & \\
\hline \multicolumn{4}{|c|}{$\beta \mathrm{TG}(\mathrm{pmol} / \mathrm{l})$} \\
\hline No. & 9 & 12 & \multirow{3}{*}{ NS } \\
\hline Mean & 1.00 & $1 \cdot 58$ & \\
\hline SD & $0 \cdot 28$ & $1 \cdot 81$ & \\
\hline
\end{tabular}

NS = Not significant. 
modifications, ${ }^{2}$ to fibrinopeptide $\mathrm{B} \beta 1-42)(\mathrm{FpB} \beta 1-42)^{3}$ with modifications ${ }^{2}$ and to $\beta$-thromboglobulin $(\beta \mathrm{TG})^{4}$ with modifications. ${ }^{2}$ Serum cholesterol and triglycerides were measured direct $^{5}$ while high density lipoprotein cholesterol (HDLC) was estimated by precipitation of $\beta$-and prebeta-lipoproteins and measurement of cholesterol in the $\alpha$-lipoprotein. ${ }^{5}$

Data from these patients were compared with data from age-matched controls (Table 1). No significant differences between patients with gout and controls were found.

Spearman rank correlation coefficients were calculated between FpA, FpB $\beta 1-42$ and BTG and lipid concentrations, alcohol consumption, and weight as the data on alcohol and weight tend not to be distributed normally. There were only two significant correlations--that is, cholesterol in mmol/l with $\mathrm{FpA}$ in $\mathrm{pmol} / \mathrm{l}$ and HDLC in mmol/l with $\mathrm{FpB} \beta 1-42$ in $\mathrm{pmol} / \mathrm{l}(\mathrm{p}<0.05)$.

Correlation results must be considered with care as this was a study on small numbers of patients. Furthermore, it must be remembered that abnormalities of coagulation detected in vitro are not necessarily present in vivo nor do they necessarily have a causal relationship with thrombosis.

We concluded that modern methods to assess coagulation and platelet function did not show any significant abnormalities in patients with primary gout.

\section{References}

1 Nossel H L, Yudelman I, Canfield R E, et al. Measurement of fibrinopeptide $\mathbf{A}$ in human blood. J Clin Invest 1974; 54: 43-53.

2 Lane D A, Ireland H, Wolff S, Boots M, Pegrum G D. Simultaneous measurement of thrombin and plasmin activities and platelet releasing stimuli in plasma. Br J Haematol 1981; 47: 630.

3 Nossel H L, Wasser J, Kaplan K L, La Gamma K S, Yudelman I, Canfield R E. Sequence of fibrinogen proteolysis and platelet release after intra-uterine infusion of hypertonic saline.J Clin Invest 1979; 64: 1371-8.

4 Bolton A E, Ludlam C A, Moore S, Pepper D S, Cash J D. Three approaches to the radioimmunoassay of human $\beta$-thromboglobulin. Br J Haematol 1976; 33: 233-8.

5 Smith L, Lucas D, Lehnus G. Automated measurement of total cholesterol and triglycerides, in 'tandem', on the Discrete Sample Analyser Guildford System 3500. Clin Chem 1979; 25: 439-42.

\title{
Long term comparison of azapropazone with allopurinol in control of chronic gout and hyperuricaemia
}

\author{
J. S. TEMPLETON \\ From the International Clinical Research Department, A. H. Robins Co Limited
}

Allopurinol is the standard agent used to lower serum urate concentration and does so by its ability to inhibit xanthine oxidase. Azapropazone is a non-steroidal anti-inflammatory drug (NSAID) that has been shown to inhibit urate monohydrate crystal-induced inflammation in the rat and in $\operatorname{man},{ }^{1}$ to reduce serum urate concentration in patients with rheumatoid arthritis, chronic gout, and hyperuricaemia ${ }^{2}$ and to be effective in the treatment of both acute and chronic gout. $^{3}$

In this study, 24 separate investigators recruited suitable patients with chronic gout or hyperuricaemia or both who had been receiving allopurinol treatment satisfactorily for at least three months before entry to the study. Patients were then allocated to one of two treatment groups, either continuing to receive allopurinol and followed up every two months for up to six months, or starting azapropazone $600 \mathrm{mg}$ twice daily and seen roughly every month for up to six months. Both groups were comparable in respect of age, sex, duration of disease, allopurinol dose at entry, diagnosis, and eligibility for the study.

Data is so far available on 155 patients who changed to azapropazone and 122 who continued to receive allopurinol. Control of serum urate concentration was comparable in both groups (Table 1). In both groups, serum urate remained remarkably constant with two points worthy of mention.

(1) Azapropazone lowered urate concentration slightly after two weeks and indeed further studies are planned to see if this in fact occurs earlier than two weeks.
(2) There is no evidence of increase in serum urate concentrations in those patients who changed from allopurinol to azapropazone. This is contrary to the findings in a group of patients in whom allopurinol treatment was suddenly discontinued. ${ }^{4}$

During the study period acute attacks of gout were less frequent in those patients taking azapropazone than in those who continued to take allopurinol. Indeed, an 'attack rate' during the first four weeks of study in those patients from both groups who could be classed as susceptible - that is, those with positive history of acute gout-showed no acute attacks in 109 patients receiving azapropazone and six acute attacks in 103 patients receiving allopurinol.

Adverse effects, particularly relating to the upper gastrointestinal tract, occurred more often in patients 